\title{
Avoidance learning after simultaneous versus serial telencephalic ablations in the goldfish
}

\author{
MAURICIO R. PAPINI \\ Universidad de Buenos Aires, Buenos Aires, Argentina
}

(J. Bruce Overmier, sponsor)

\begin{abstract}
The effects of simultaneous and serial bilateral ablation of the goldfish telencephalon on the retention of an avoidance response was studied. On the basis of research in mammals, it was expected that the serial procedure would produce significant savings in the retention of avoidance learning, which is otherwise significantly impaired after simultaneous bilateral ablations of the telencephalon. The retention of the avoidance task learned prior to the ablations was unaffected by the serial procedure.
\end{abstract}

The study of the relationship between teleost telencephalon function and acquired and species-typical behavior has been carried out mainly through the use of ablation procedures (de Bruin, 1980; Hollis \& Overmier, 1978; Savage, 1980). Typically, the ablation is performed simultaneously on both hemispheres, and behavioral changes are determined by appropriate comparisons with sham-operated animals.

The effects of simultaneous bilateral ablations of the telencephalon on acquired responses have, to a great extent, depended upon the tasks designed to detect such deficits. For example, forebrainless fish have shown no deficits on classical conditioning experiments (Farr \& Savage, 1978; Overmier \& Curnow, 1969; Overmier \& Savage, 1974) and on relatively simple instrumental tasks (Savage, 1969a). However, telencephalon ablation produced detectable deficits on habituation of the cardiac arousal response (Laming \& McKee, 1981), foodreinforced responses (Overmier \& Patten, 1982; Savage, 1969a), and complex maze performance (Warren, 1961). Avoidance behaviors have been dramatically disrupted by such ablations (Hainsworth, Overmier, \& Snowdon, 1967; Kaplan \& Aronson, 1967; Overmier \& Flood, 1969; Overmier \& Gross, 1974; Savage, 1969b).

The effect of telencephalon ablation on avoidance learning has received comparatively more attention from researchers interested in the functions of teleost telencephalon, in part due to its magnitude and reliability under a wide varety of conditions. Although the ablation was found to exert its influence on both de novo acquisition

This research was carried out at the University of Minnesota while the author was supported by a fellowship from Consejo Nacional de Investigaciones Científicas y Técnicas, Argentina. The author wishes to thank J. B. Overmier for his continuous support and for valuable contributions to this research project. Requests for reprints should be sent to M. R. Papini, Departamento de Ciencias Biologicas, Universidad de Buenos Aires, Ciudad Universitaria-Pab. II, 1428-Buenos Aires, Argentina. and retention, avoidance behaviors seem to recover and reach an unstable but relatively high level (Hainsworth et al., 1967; Savage, 1969b). The present research is an attempt to identify some of the factors affecting behavioral recovery after damage to the telencephalon in the goldfish.

A different, although complementary, approach to the phenomenon of behavioral recovery would be to ask whether different types of ablation procedures would allow the behavior to be recovered faster and to a higher level. From research on mammals, it is known that the serial ablation procedure has, in general, facilitating effects on behavioral recovery from brain damage (Finger, Walbran, \& Stein, 1973). Various kinds of behavior have been shown to be spared after sequential lesions, as opposed to simultaneous lesions of similar extent. This "serial lesion effect"' has been found in learning situations including discriminative avoidance in rats after lesions in the occipital neocortex (Glendenning, 1972; Petrinovich \& Bliss, 1966; Petrinovich \& Carew, 1969; Thompson, 1960) and two-way shuttle avoidance after lesions in the lateral septal area in the rat (Kouba \& Bussey, 1973).

The experiment reported in the present paper attempted to characterize the retention of instrumental avoidance behavior in fish that had been submitted to serial, simultaneous, and sham ablations of the telencephalon. The experiment was a partial replication of another (Overmier \& Papini, in press); it used a higher level of shock intensity in the avoidance training because level of "arousal" was known to be important in postoperative retention.

\section{METHOD}

The subjects were 18 goldfish (Carassius auratus) $8-12 \mathrm{~cm}$ long, housed individually in 20 -liter aquaria at $21^{\circ} \mathrm{C}$ and $\mathrm{pH}$ 7.3. The fish were assigned to three groups of equal size.

Avoidance training took place in a $46.5-\mathrm{cm}$ shuttlebox divided into two equal chambers by a $7.5-\mathrm{cm}$ barrier. Water depth was $9-\mathrm{cm}$. The device was modeled after that of Horner, Longo, and Bitterman (1961). 
The chambers were illuminated by white light during the intertrial interval. The warning signal was a change to red illumination throughout. The shock to be avoided was $10 \mathrm{~V}$ ac pulsed $(105 \mathrm{msec}$ on, $320 \mathrm{msec}$ off) delivered through longitudinal electrode walls. The interval between the onset of the warning signal and the scheduled onset of the shock was $10 \mathrm{sec}$. The warning stimulus overlapped the shock, which lasted up to $2 \mathrm{sec}$. A response terminated the trial by ending the warning sig nal and the shock (escape) or ending the warning signal and preventing the shock if shock had not yet come on (avoidance). The intertrial interval averaged $92.4 \mathrm{sec}$. Each daily session consisted of 10 trials.

First, all fish were adapted to the apparatus for two sessions, and spontaneous crossings were recorded. Then avoidance training began and continued until the subjects had met a mastery criterion of six consecutive sessions in which the percentage avoidance equalled or exceeded $70 \%$ on at least five of the sessions. Upon reaching criterion, the fish began to receive different surgical treatments.

For surgery, the fish were anesthetized with tricaine methanosulfonate $(.5 \mathrm{mg} / \mathrm{ml})$ and mounted in a special sponge clamp holder. Gills were continuously bathed while the fish was in the holder. A rectangular flap about $4 \mathrm{~mm}^{2}$ was reflected over the anterior portion of the brain, and the fatty superficial tissue was aspirated in all fish. In addition, some fish had one (unilateral) or both (bilateral) hemispheres of the telencephalon aspirated. The wound was then filled with Gelfoam, and the flap was closed and secured with dental cement. The fish were then returned to their compartments for $48 \mathrm{~h}$ before any further treatments.

Postexperimental verification of the ablations revealed that one fish in Group S+S (see below) received a small lesion in the dorsal telencephalon. This fish was therefore excluded from the experiment. The ablations were quite uniform in achieving removal of the telencephalic hemispheres with no detected damage to the optic tectum or to the preoptic nucleus area. Representative brains from each group are shown in Figure 1.

There were three treatment groups. Group $U+U$ received a unilateral ablation of the telencephalon followed (after $48 \mathrm{~h}$ ) by 10 daily sessions of interoperative training (IOT) on the avoidance task and then a second unilateral hemispherectomy. Group $S+B$ received a sham operation followed (after $48 \mathrm{~h}$ ) by 10 sessions of IOT and then bilateral ablation of the telencephalon. Group $S+S$ received a sham operation followed by 10 sessions of IOT and then a second sham operation.

Forty-eight hours after the second operation, all groups were tested for retention of the avoidance task for two sessions. The avoidance performance of the three groups during acquisition and retention sessions constitute the data of most interest.

\section{RESULTS}

Individual subjects' avoidance scores were computed on the basis of performance in blocks of two sessions and were subjected to analyses of variance for each phase of the experiment. These data for the acquisition and retention behavioral phases of the experiment are shown in Figure 2.

During adaptation, there was little spontaneous crossing of the barrier on the blank trials. Analysis of Variance detected no between-groups differences.

The original training on the avoidance task was carried out until each fish had reached the criterion of mastery, and all groups were averaging between $78 \%$ and $88 \%$ avoidance by the end of original training. The subjects reached criterion in an average of 7.7 session. Analysis of variance (groups $\times 2$ session blocks, unequal ns) of avoidance performances of the criterion run detected no significant differences among groups, but did detect an effect of blocks of training $[\mathrm{F}(2,28)=15.62, \mathrm{p}<.01]$.

The next behavioral phase of the experiment involved

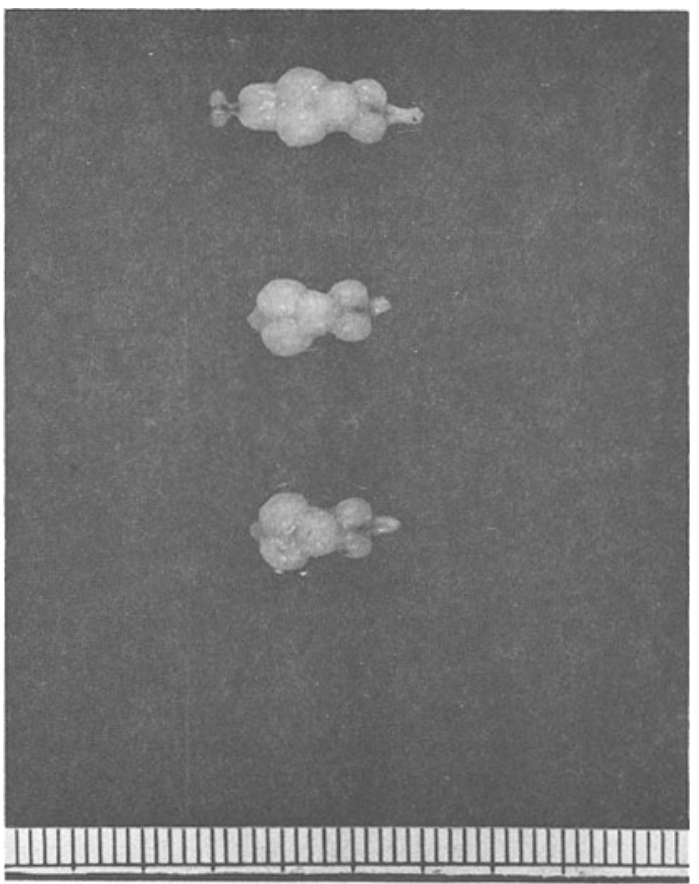

Figure 1. Representative brains from each group and a metric scale. Brains are from Groups $S+S$ (above), $U+U$ (center), and $S+B$ (below).

the 10 days of IOT for Groups $\mathbf{S}+\mathrm{S}, \mathrm{S}+\mathrm{B}$, and $\mathrm{U}+\mathrm{U}$. Performance for all groups was relatively high: It did not fall below $80 \%$ and, hence, exceeded criterion throughout. Only for Group $U+U$ do the data potentially reflect the effect of a lesion. An analysis of variance detected a numerically small, but significant, effect of groups $[F(2,14)=7.36, p<.01]$. Follow-up pairwise comparison between the unilaterally ablated group and the two shams was significant $[\mathrm{t}(14)=3.51, \mathrm{p}<.01]$. Additional analysis showed the intertrial activity level of the unilateral group to be less; pairwise comparisons showed Group $\mathrm{U}+\mathrm{U}$ differed from both Groups $\mathrm{S}+\mathrm{S}$ and $\mathrm{S}+\mathrm{B}$ $[\operatorname{ts}(14) \geq 3.5, \mathrm{p}<.01]$.

Following the second behavioral phase, which consisted of IOT, all subjects received a sham (Group $S+S$ ), unilateral (Group $U+U$ ), and bilateral (Group $S+B$ ) ablation, and then, $48 \mathrm{~h}$ after the last surgical procedure, were tested for retention of the avoidance task using the training procedures. These are the data of central interest.

The group subjected to two sham operations 12 days apart, Group $S+S$, continued to perform at a very high level. The story was quite different for the ablated animals, which showed substantial deficits in retention. Analysis of variance indicated an effect of groups $[\mathrm{F}(2,14)$ $=9.7, \mathrm{p}<.01]$. Pairwise comparison confirmed that the two ablated groups differed from Group S+S [ts(14) $\geq 2.1, \mathrm{p}<.05$ ]. but not from each other. This difference in avoidance was paralleled by similar differences in intertrial activity: Both Groups $U+U$ and $S+B$ differed 


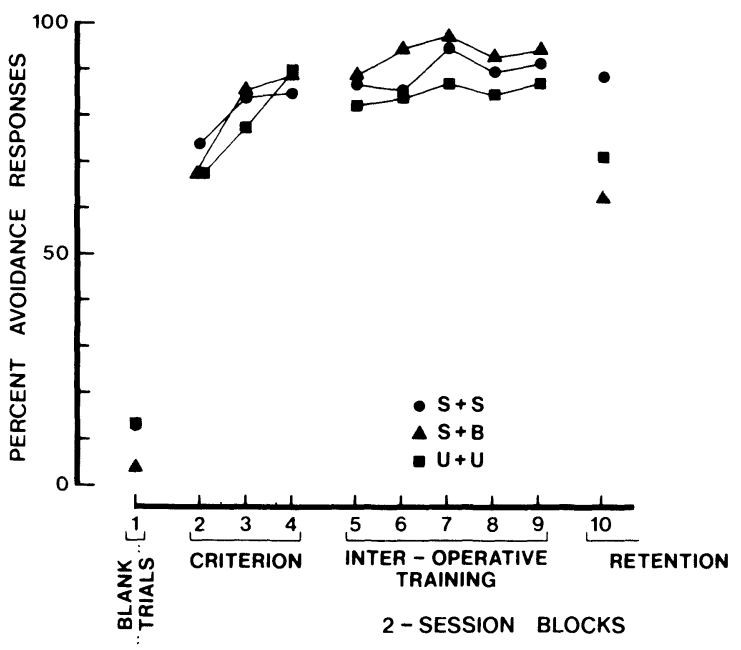

Figure 2. Percent avoidance responses for Groups $S+S, S+B$, and $\mathrm{U}+\mathrm{U}$ during each training phase.

from Group $S+S$ [ts $(14) \geq 8.7, p<.01]$, but not from each other. Group $U+U$, which had been only mildly insensitive to the first unilateral operation, showed a marked decrement in performance after the second unilateral ablation. Finally, the deficits seen in Group S+B were not greater than those seen in Group $U+U$, which suggested that two-stage serial ablation of the teleost telencephalon results in functionally similar deficits in retention of a shuttlebox avoidance behavior, as does one-stage bilateral ablation.

\section{DISCUSSION}

Reviews of the literature (e.g., Finger et al., 1973) confirm the serial lesion effect in mice, rats, cats, dogs, monkeys, and man subjected to a wide variety of lesions on a wide variety of brain loci and tested in a variety of tasks. Yet no evidence for a serial lesion effect was found in these telencephalon-ablated fish. On occasion, others have failed to find a serial lesion effect in mammals (e.g., Kircher, Braun, Meyer, \& Meyer, 1970), but such failure may be attributable to lack of IOT. Absence of a serial lesion effect in this experiment cannot be attributed to a failure to provide task-relevant interoperative experience because the serial ablation group received 10 days of training on the avoidance task between the two unilateral ablations.

The absence of a serial lesion effect is somewhat surprising in the historical context. Moreover, the design used in the present experiment could be inferred to have a slight bias in favor of the serial group because the time to recover following the initial invasion of the brain was longer for the serial group (see Kassel \& Davis, 1977; Meyer et al., 1958); nevertheless, no serial lesion effect was observed.

This experiment essentially replicated the results of an earlier experiment that used lower shock levels $-4 \mathrm{~V}$ ac(Overmier \& Papini, in press). Although absolute levels of performance were somewhat higher here, the patterns of effects among sham, simultaneous, and serial ablation groups were the same. In particular, in retention tests both ablated groups were inferior to the sham group, but these ablated groups did not differ from each other significantly. Using a different level of motivating stimulus did not alter the pattern of results. The serial procedure did not enhance retention of the preoperatively trained avoidance even when the interoperative training was given.

Even though the serial ablation procedure is often conceived as a means of sparing a specific learning process that has begun before ablation or damage to the central nervous system (Bodart, Hata, Meyer, \& Meyer, 1980; Meyer \& Meyer, 1977), one could also speculate that behavioral sparing might be rather nonspecific with respect to the task already learned by the animal. In other words, the serial procedure could facilitate nonspecific learning capabilities by leaving the rest of the nervous system in a, so to speak, more plastic state. Following this reasoning, it might be wise to include a task that demanded the learning of a somewhat new feature of the environment, such as a "reversal" learning phase, as a relatively simple way to test this basic idea (see LeVere \& Morelock, 1973).

Intertrial activity was included as a measure because it might provide an assessment of general effects of telencephalic manipulations separate from specific discriminated avoidance behavior. Ablations decreased both avoidance performance and "spontaneous" intertrial crossings of the barrier. This consideration would suggest that the telencephalon of the goldfish is not exclusively involved in memory or cued response evocation but may well involve general arousal functions, as others have suggested (Aronson \& Kaplan, 1968).

\section{REFERENCES}

Aronson, L. R., \& Kaplan, H. (1968). Function of the teleostean forebrain. In D. Ingle (Ed.), The central nervous system and fish behavior (pp. 107-125). Chicago: University of Chicago Press.

Bodart, D. J., Hata, M. G., Meyer, D. R., \& Meyer, P. M. (1980). The Thompson effect is a function of the presence or absence of preoperative memories. Physiological Psychology, 8, 15-19.

DE BRUIN, J.P.C. (1980). Telencephalon and behavior in teleost fish: A neuroethological approach. In S. O. E. Ebbesson (Ed.), Comparative neurology of the telencephalon (pp. 175-201). New York: Plenum Press.

FARR, E. J., \& SAVAGE, G. E. (1978). First- and second-order conditioning in goldfish and their relation to the telencephalon. Behavioral Biology, 22, 50-59.

Finger, S., Walbran, B., \& STEIn, D. (1973). Brain damage and behavioral recovery: Serial lesion phenomena. Brain Research, 63, 1-18.

GLENDENNING, R. L. (1972). Effects of training between two unilateral lesions of visual cortex upon ultimate retention of black-white discrimination habits by rats. Journal of Comparative and Physiological Psychology, 80, 216-229.

Hainsworth, F. R., Overmier, J. B., \& Snowdon, C. T. (1967). Specific and permanent deficits in instrumental avoidance responding following forebrain ablation in the goldfish. Journal of Comparative and Physiological Psychology, 63, 111-116.

Hollis, K. L., \& Overmier, J. B. (1978). The function of the teleost telencephalon in behavior: A reinforcement mediator. In D. I. Mostofsky (Ed.), The behavior of fish and other aquatic animals (pp. 137-195). New York: Academic Press.

HoRner, J. L., LoNGo, N., \& Bitterman, M. R. (1961). A shuttlebox for the fish and a control circuit of general applicability. American Journal of Psychology, 74, 114-120.

Kaplan, H., \& ARONSON, L. R. (1967). Effect of forebrain ablation on the performance of conditioned avoidance response in the teleost fish Tilapia H. macrocephala. Animal Behaviour, 15, 438-448.

KaSSEL, J., \& DAVIS, R. E. )1977). Recovery of function following simultaneous and serial telencephalon ablation in the teleost, Macropodus opercularis. Behavioral Biology, 21, 489-499.

Kircher, K. A., Braun, J. J., Meyer, D. R., \& Meyer, P. M. (1970). Equivalence of simultaneous and successive neocortical ablations in production of impairments of retention of black-white habits in rats. Journal of Comparative and Physiological Psychology, 71, 420-425.

Kouba, F. C., \& Bussey, M. E. (1973). Two-way shuttle avoidance after simultaneous and staged lateral septal lesions in the rat. Bulletin of the Psychonomic Society, 2, 111-112.

LAMING, P. R., \& MCKeE, M. (1981). Deficits in habituation of cardiac arousal responses incurred by telencephalic ablation in goldfish, Carassius auratus, and their relation to other telencephalic functions. Journal of Comparative and Physiological Psychology, 95, 460-467. 
LeVere, T. E., \& MoReLocK, G. W. (1973). The nature of visual recovery following posterior decortication in the hooded rat. Journal Comparative and Physiological Psychology, 83, 62-67.

MeYer, D. R., IssaC, W., \& MAHER, B. (1958). The role of stimulation in spontaneous reorganization of visual habits. Journal of Comparative and Physiological Psychology, 51, 546-548.

MEYeR, D. R., \& MEYER, P. M. (1977). Dynamics and bases of recoveries of functions after injuries to the cerebral cortex. Physiological Psychology, 5, 133-165.

Overmier, J. B., \& CURNow, P. F. (1969). Classical conditioning, pseudoconditioning, and sensitization in "normal" and forebrainless goldfish. Journal of Comparative and Physiological Psychology, 68, 193-198.

Overmier, J. B., \& Flood, N. B. (1969). Passive avoidance in forebrain ablated teleost fish, Carassius auratus. Physiology \& Behavior, 4, 791-794.

Overmier, J. B., \& Gross, D. (1974). Effects of telencephalic ablation upon nest-building and avoidance behaviors in East Africa mouthbreeding fish, Tilapia mossambica. Behavioral Biology, 12, 211-222.

Overmier, J. B., \& PAPINI, M. R. (in press). Serial ablations of the telencephalon and avoidance learning by goldfish (Carassius auratus). Behavioral Neuroscience.

Overmier, J. B., \& Patten, R. L. (1982). Teleost telencephalon and memory for delayed reinforcers. Physiological Psychology, 10, 74-78.

OVERmier, J. B., \& SAVAGE, G. E. (1974). Effects of telencephalic ablation on trace classical conditioning of heart rate in goldfish. Experimental Neurology, 42, 339-346.
Petrinovich, L., \& Buiss, D. (1966). Retention of a learned brightness discrimination following ablations of the occipital cortex in the rat. Journal of Comparative and Physiological Psychology, 61, 136-138.

Petrinovich, L., \& CAREW, T. J. (1969). Interaction of neocortical lesion size and interoperative experience in retention of a learned brightness discrimination. Journal of Comparative and Physiological Psychology, 68, 451-454.

SAVAGE, G E. (1969a). Some preliminary observations on the role of the telencephalon in food-reinforced behaviour in the goldfish, Carassius auratus. Animal Behaviour, 17, 760-772.

SAvAGE, G. E. (1969b). Telencephalic lesions and avoidance behaviour in the goldfish (Carassius auratus). Animal Behaviour, 17, 362-373.

SAVAGE, G. E. (1980). The fish telencephalon and its relation to learning. In S. O. E. Ebbesson (Ed.), Comparative neurology of the telencephalon (pp. 129-174). New York: Plenum Press.

THOMPSON, R. (1960). Retention of a brightness discrimination following neocortical damage in the rat. Journal of Comparative and Physiological Psychology, 53, 212-215.

WARREN, J. M. (1961). The effect of telencephalon injuries on learning by paradise fish, Macropodus opercularis. Journal of Comparative and Physiological Psychology, 54, 130-132.

(Manuscript received for publication August 17, 1984.) 